\title{
Refugees' Access to Systemic, Oral and Mental Healthcare Services
}

\author{
Munjed Farid Al Qutob* \\ Private practice, London, $U K$
}

Received: October 26, 2016; Accepted: December 17, 2016; Published: December 29, 2016

*Corresponding author: Munjed Farid Al Qutob, Private practice, London, UK. E-mail: malqutob@hotmail.com

\section{Letter to Letter}

The migration crisis is one of the most pressing challenges facing the entire international community today as human displacement is at its highest. Refugees place tremendous burdens on host countries, sapping public resources. The number is steadily increasing with the ongoing fighting in Syria as the original source of refugees and asylum seekers. This issue is European as it is Middle Eastern as more than one million refugees have arrived in Germany within the last year alone. The growing influx of vulnerable populations poses multiple challenges to host countries especially in terms of their resilience and preparedness of health systems to respond to such humanitarian disasters of biblical magnitude and the access of refugees to healthcare services. It is widely accepted that refugees and displaced populations are more vulnerable to physical and mental health problems than the general population as a consequence of their traumatic migration journeys, difficulties in resettlement, depression, human rights violations. Refugees have also a high rate of malnutrition, sexual and gender based violence, communicable and non-communicable diseases and lack of access to vital medicines and vaccines. One point that has been grossly missed in the debate is the inextricable link between dentistry and public health. The inextricable link between oral and systemic health is embedded within a web of interconnected and indivisible relationships, in a system of political and social relations, in a web of mutually influencing factors. Oral health affects a multitude of chronic diseases. It can adversely affect our quality of life, the way we speak, eat, live, Google and behave apart from the considerable pain that could be translated into days, weeks and years of workers' and students' absence and their lack of productivity [1]. Refugees' access to healthcare services varies from country to another. Researchers are invited to explore refugees' access to oral health services in both developed countries such as Germany or the UK and developing countries such as the Hashemite Kingdom of Jordan (the largest host of refugees across the globe), and the barriers that impede refugees' access to seek healthcare services (cultural, political, social, economic and linguistic). Before this, there is an urgent call to reform and strengthen global institutions and international law for health in order to bind a variety of stakeholders and actors and think and act holistically, translating sustainable development agendas into practical realities on the ground.

\section{References}

1. Aubrey Sheiham. Oral health, general health and quality of life. Bulletin of the World Health Organisation. 2005;83(9):641-720. 